\title{
Estimated and forecasted trends in domain specific time-use and energy expenditure among adults in Russia
}

Tracy Dearth-Wesley, Barry M Popkin and Shu Wen Ng*

\begin{abstract}
Background: Examination of historical trends and projections in estimated energy expenditure in Russia is important given the country's economic downturns and growth.

Methods: Nationally representative data from the Russia Longitudinal Monitoring Survey (RLMS) from 1995-2011 was used to determine the metabolic equivalents of task (MET)-hours per week from occupational, domestic, travel, and active leisure physical activity (PA) domains, as well as sedentary leisure time (hours per week) among adults 18-60 years. Additionally, we projected what these values would be like in 2020 and 2030 if observed trends continue.

Results: Among male adults, the largest contributor to total PA was occupational PA followed by travel PA. In contrast, domestic PA followed by occupational PA contributed most to total PA among female adults. Total PA was 282.9 MET-hours per week in 1995 and declined to 231.7 in 2011. Total PA is projected to decrease to 216.5 MET-hours per week in 2020 and to 193.0 MET-hours per week in 2030. The greatest relative declines are occurring in travel PA. Female adults are also exhibiting significant declines in domestic PA. Changes in occupational and active leisure PA are less distinct.
\end{abstract}

Conclusions: Policies and initiatives are needed to counteract the long-term decline of overall physical activity linked with a modernizing lifestyle and economy among Russian adults.

Keywords: Physical activity, Time-use, Sedentary, Active transport, Movement, Russia

\section{Background}

Initiatives designed to reduce the global burden of overweight and obesity require understanding of environmental and individual factors affecting dietary and physical activity (PA) patterns and monitoring of these patterns over time and across countries [1-4]. With respect to PA, the International Physical Activity Questionnaire (IPAQ) and the Global Physical Activity Questionnaire (GPAQ) enable surveillance of PA and international comparisons [5-7]. More rigorous examination of PA, such as more detailed time allocation and energy expenditure in domainspecific activities, can be achieved through utilization of longitudinal and cross-sectional country-specific datasets [8-12]. Past analyses of country-specific data from the

\footnotetext{
* Correspondence: shuwen@unc.edu

Department of Nutrition and Carolina Population Center, University of North Carolina at Chapel Hill, Chapel Hill, NC, USA
}

United States, the United Kingdom, China, Brazil and India have described historical trends in estimated average energy expenditure in four domains of activity (occupation, domestic production, travel and active leisure) and sedentary time in adults, and also projected changes in energy expenditure in these domains and sedentary time for 2020 and 2030 [9]. Extension of this research on historical trends and projections in energy expenditure to include Russia, a country that ranks 9th in the world by population ( 143 million people) [13], would strengthen the research base for more thorough international PA comparisons and contribute to more effective domain-specific initiatives [9].

Examination of historical trends and projections in estimated energy expenditure in Russia is additionally important given the country's economic downturns and growth. The Russian economy suffered a major depression in the

\section{Biomed Central}


early to mid-1990s, with a brief recovery in 1996-7, only to face a serious financial crisis in 1998. Following this crisis, the economy recovered for the next 10 years, posting gross domestic product growth ranging from 4.7 to $10.0 \%$ $[14,15]$. After a smaller recession in 2008-2009, the economy is recovering [16]. While some research has looked at the impact of these economic transitions on dietary patterns [17-19], less is known about how these transitions influenced PA across the domains and what can be expected in the next 10-20 years. PA projections not only provide valuable insight into potential PA patterns if no actions are taken but also help prioritize the development and implementation of domain-specific PA initiatives.

Particular focus on understanding how these economic transitions influence occupational PA is key, given occupational PA is a primary contributor to total PA [9]. Additionally, the Russian dataset includes occupational data that measures both the time and intensity of occupational activities (e.g., time spent in a usual workday doing moderate physical effort while standing or in movement), thus providing a unique opportunity to compare three distinct approaches for determining metabolic equivalents of task (MET) values for occupational PA. While the first approach involves assigning MET values to occupations or occupational categories using the Compendium of Physical Activities [20], the second and third approaches utilize different measures of time and intensity from occupational activities to determine MET values for occupational categories. Comparison of these approaches would yield methodological evidence important for determining a robust approach for measuring occupational PA.

There have been limited analyses of child PA patterns in Russia, and little research has been conducted on adults $[21,22]$. Using cross-sectional data from the nationally representative Russia Longitudinal Monitoring Survey (RLMS), we examined PA patterns in male and female adults (18-60 years) over a 16-year time period (1995 to 2011). PA patterns included 4 activity domains (occupation, domestic production, travel, and active leisure) and sedentary time. Our primary study objectives were to (1) compare three approaches for determining MET values for occupational PA, (2) estimate average energy expenditure for the activity domains and sedentary time and look at changes over time, and (3) forecast estimated average energy expenditure for PA domains in 2020 and 2030.

\section{Methods}

Data

The RLMS is a de-identified publicly available data source that includes a series of nationally representative, household-based surveys developed to examine the effects of Russian reforms on the health and economic well-being of households and individuals in the Russian
Federation [23-26]. A multi-stage probability sample was used. While the RLMS was not specifically designed to examine PA, participants were asked to report on the frequency and duration of various activities across occupation, domestic production, travel, active leisure, and sedentary domains. Some Rounds of the RLMS also asked about the intensity of occupational activities. Data from RLMS Rounds 6 to 20 were analyzed, spanning a 16-year time period including surveys conducted in 1995, 1996, 1998, and 2000-2011. The number of sampled households was approximately 4,000 for Rounds 6 to 18 (1995-2008) and increased to approximately 6,000 for Rounds 19 and 20 (2010-2011).

\section{Estimating average energy expenditure for PA domains}

Estimated averages of energy expenditure among adults in Russia were determined for 4 PA domains: occupational, domestic, travel, and active leisure. Additionally, we attempted to estimate sedentary leisure time per week for a subset of the adult population based on available data (Rounds 10-11). This subset included adults who previously participated in the RLMS Child Survey, in which time spent watching television or videos was reported. Note that we do not account for time spent during and energy expended from sleep or personal/selfcare activities, as time spent sleeping was only measured in Rounds 5-8 and personal/self-care activities were not measured in the RLMS surveys.

Occupational PA included self-reported measures of time spent in primary and secondary occupations. Determination of estimated MET values for these occupations was done using three approaches. For all three approaches, the occupations were first coded into 10 main categories (e.g., professionals, clerks, service and market workers, etc.), according to the International Standard Classification of Occupations: ISCO-88 [27]. The ISCO classification of jobs in the RLMS was previously determined using computer and coder analyses of responses to various occupation questions along with careful consideration of the Russian labor market [28]. Following the categorization of occupations, the most frequently reported occupations within each occupational category were determined (Table 1). Using this information, the first approach (Approach A) assigned MET values to these occupations or more generally to the occupational category using the Compendium of Physical Activity [20]. The MET values within each occupational category were then averaged to determine a MET value for each occupational group (Table 1). This approach for MET value assignment was necessary given the previously determined ISCO classifications; comparison with other approaches, such as that developed for the American Time Use Survey [29], was done where there was some general overlap in the main occupational categories. 
Table 1 Occupational categories, frequently reported occupations, compendium codes and descriptions, and average MET values based on 3 approaches ${ }^{1}$

\begin{tabular}{|c|c|c|c|c|c|c|}
\hline \multirow[t]{2}{*}{ Occupational categories } & \multirow[t]{2}{*}{ Most frequently reported occupations } & \multirow[t]{2}{*}{2011 Compendium codes and descriptions } & \multirow{2}{*}{$\begin{array}{l}2011 \text { MET } \\
\text { value }\end{array}$} & \multicolumn{3}{|c|}{ Average MET value } \\
\hline & & & & Approach $A^{2}$ & ${\text { Approach } B^{3}}^{3}$ & Approach $\mathrm{C}^{4}$ \\
\hline \multirow{3}{*}{$\begin{array}{l}\text { Legislators, Senior Managers, } \\
\text { Officials }\end{array}$} & General Mgr, not classified (28.7\%) & 11472 manager, property & 1.8 & 2.3 & 2.5 & 2.5 \\
\hline & General Mgr Wholesale (18.5\%) & 11585 sitting meetings, light effort, general & 1.5 & & & \\
\hline & Other Dept Mgr (13.2\%) & 11792 walking on job, $3.0 \mathrm{mph}$, moderate speed & 3.5 & & & \\
\hline \multirow[t]{3}{*}{ Professionals } & Architect/Engineer, not classified (13.0\%) & 11135 engineer (e.g., mechanical/electrical) & 1.8 & 2.3 & 2.1 & 2.4 \\
\hline & Teachers (13.9\%) & 11585 sitting meetings, light effort, general & 1.5 & & & \\
\hline & Doctors (9.0\%) & 11792 walking on job, $3.0 \mathrm{mph}$, moderate & 3.5 & & & \\
\hline \multirow[t]{3}{*}{$\begin{array}{l}\text { Technicians and Associate } \\
\text { Professionals }\end{array}$} & Bookkeepers (18.0\%) & $\begin{array}{l}11610 \text { standing, light/moderate effort } \\
\text { (e.g., nursing) }\end{array}$ & 3.0 & 2.7 & 2.7 & 2.5 \\
\hline & Nurses (13.5\%) & 11580 sitting tasks, light effort & 1.5 & & & \\
\hline & Technicians, not classified (5.6\%) & 11792 walking on job, $3.0 \mathrm{mph}$, moderate & 3.5 & & & \\
\hline \multirow[t]{3}{*}{ Clerks } & Store Clerks (22.9\%) & 11600 standing tasks, light effort (e.g., store clerk) & 3.0 & 2.3 & 2.3 & 2.2 \\
\hline & Cashiers (12.5\%) & 11580 sitting tasks, light effort (e.g., office work) & 1.5 & & & \\
\hline & Secretary (11.7\%) & & & & & \\
\hline \multirow[t]{4}{*}{ Service and Market Workers } & Shop salespersons (47.2\%) & 11600 standing tasks, light effort (e.g., store clerk) & 3.0 & $4.0^{*}$ & 3.8 & 3.7 \\
\hline & Police officers (10.3\%) & 11528 police, making an arrest, standing & 4.0 & & & \\
\hline & Cooks $(10.3 \%)$ & 11115 cook, chef & 2.5 & & & \\
\hline & Stall/market salespersons (8.0\%) & $\begin{array}{l}11060 \text { carrying moderate loads upstairs, } \\
\text { moving boxes }\end{array}$ & 8.0 & & & \\
\hline \multirow{4}{*}{$\begin{array}{l}\text { Skilled Agricultural and } \\
\text { Fishery Workers }\end{array}$} & Forestry workers and loggers (35.0\%) & 11264 forestry, moderate effort & 4.5 & 4.7 & 4.8 & 3.5 \\
\hline & $\begin{array}{l}\text { Market-oriented crop/animal } \\
\text { producer }(12.7 \%)\end{array}$ & 11192 farming, taking care of animals, general & 4.5 & & & \\
\hline & Market-oriented animal producer, & 11146 farming, moderate effort & 4.8 & & & \\
\hline & & 11248 fishing, commercial, moderate effort & 5.0 & & & \\
\hline \multirow[t]{6}{*}{ Craft and Related Trades } & $\begin{array}{l}\text { Agricultural/industrial-machinery } \\
\text { mechanics (15.9\%) }\end{array}$ & 11450 machine tooling, moderate effort & 5.0 & 3.8 & 5.0 & 3.7 \\
\hline & Welders (10.3\%) & 11430 machine tooling (e.g., welding) & 3.0 & & & \\
\hline & Mechanics (8.5\%) & 11420 locksmith & 3.0 & & & \\
\hline & Locksmith (7.4\%) & 11040 carpentry, general, moderate effort & 4.3 & & & \\
\hline & Carpenters (6.7\%) & & & & & \\
\hline & Heavy truck and lorry drivers (16.5\%) & 11766 truck driving, loading and unloading & 6.5 & 4.0 & 4.0 & 3.1 \\
\hline
\end{tabular}


Table 1 Occupational categories, frequently reported occupations, compendium codes and descriptions, and average MET values based on 3 approaches (Continued)

\begin{tabular}{llll}
\hline $\begin{array}{l}\text { Plant and Machine Operators } \\
\text { and Assemblers }\end{array}$ & Driver (12.1\%) & $\begin{array}{l}\text { l1610 standing, moderate effort } \\
\text { (e.g., assemble heavy parts) }\end{array}$ & 3.0 \\
& Motorized farm/forestry operator (10.8\%) & $\begin{array}{l}11500 \text { operating heavy duty } \\
\text { equipment, automated }\end{array}$ & 2.5 \\
Elementary (Unskilled) & Domestic helpers/cleaners (23.0\%) & 11126 custodial work, moderate effort & 3.8 \\
Occupations & Building caretakers (20.4\%) & 11476 manual/unskilled labor, general & 4.5 \\
& Farmhand/laborers (17.5\%) & 11146 farming, moderate effort & 4.4 \\
Army & Armed forces & 11585 sitting meetings, light effort, general & 4.8 \\
& & 11792 walking on job, 3.0 mph, moderate & 3.5 \\
\hline
\end{tabular}

${ }^{1}$ Russia Longitudinal Monitoring Survey.

${ }^{2}$ Used MET values for occupations included in the 2011 Compendium of Physical Activities.

${ }^{3}$ Used significant and medium physical effort and sitting measures from a usual workday.

${ }^{4}$ Used sitting, standing, and walking measures from a usual workday.

*An average value for standing tasks and carrying moderate loads upstairs was determined. This value (5.5) was averaged with MET values for police and cook to determine the average MET value for service and market workers. 
The second approach (Approach B) for estimating MET values for occupational categories utilized time and intensity measures for work activities from RLMS Rounds 6 to 11 (1996 to 2002). In these surveys, participants were asked about time spent in a usual workday from heavy and medium physical effort (while standing or in movement) and from sitting. The reported time spent in each work activity was multiplied by the associated MET value (e.g., 6.5 MET value for heavy physical effort based on the Compendium code: 11830 walking or walk downstairs or standing, carrying objects about 50 to 74 pounds). The total MET-hours per day was calculated by summing the MET values from heavy and medium physical effort and sitting, and this value was divided by the total hours working per day to get an estimated MET value per hour for the occupation. Average MET values per hour were determined for each occupational category and are shown in Table 1.

The third approach (Approach C) also used time and intensity measures for work activities from the RLMS Rounds 6 to 11 (1996-2002). These surveys asked participants about time spent in a usual workday from sitting, standing, or walking (not carrying a load). The reported time spent in each work activity was multiplied by the associated MET value (e.g., 1.5 MET value for sitting based on the Compendium code: 11585 sitting meetings, light effort, general). The total MET-hours per day was calculated by summing the MET values from sitting, standing, and walking, and this value was divided by the total hours working per day to get an estimated MET value per hour for the occupation. As with the previous two approaches, average MET values per hour using Approach $\mathrm{C}$ were determined for each occupational category and are included in Table 1.

Comparison of the three approaches showed consistency across almost all occupational categories. In comparing Approaches A and B, MET values for all but one occupational category were within $<0.3$ METs of each other (Table 1). For the "Craft and related trades" occupational category, the average MET value using Approach A was lower than Approach B (3.8 and 5.0, respectively). More variation was seen in the average MET values as determined by Approach $\mathrm{C}$ versus those from Approaches A and $B$. In particular, lower average MET values were found from Approach $\mathrm{C}$ for the more labor-intensive occupational categories (e.g., skilled agricultural and fishery workers, plant and machine operators and assemblers). These lower average MET values were expected, given the walking variable used in Approach $\mathrm{C}$ measures walking not carrying a load. Therefore, carrying heavier loads typical of these more labor-intensive occupations is not accounted for in Approach C.

To determine estimated energy expenditure for occupational PA, the average MET values from Approach B were used. This approach was chosen given its incorporation of time and more complete intensity measures of occupational PA specific to our sample population. The average MET-hours for each occupational category were multiplied by weekly measures of time spent in primary and secondary occupations. For primary occupations, total MET-hours per day were multiplied by 5 to derive the MET-hours per week measure. The 5-day work week measure for primary occupation was determined using RLMS data and examining the ratio of reported hours in a usual work week to reported hours in a usual work day (i.e., average ratio across survey years was 4.97). For secondary occupations, the total hours per week measure was determined by dividing the reported secondary work hours in the last 30 days by four; this value was multiplied by the MET-hours per day value from secondary work.

For the domestic, travel, and active leisure domains, self-reported measures of time spent in the different domains were multiplied by appropriate estimated MET values using the Compendium of Physical Activity [20]. Due to limitations on the questions asked, travel PA only included walking and did not include other modes of travel such as bicycling, taking public transit or driving. Domestic and active leisure PA included various subdomain activities. Subdomain activities for domestic PA consisted of preparing food, washing dishes, cleaning, looking for/purchasing food, laundry, child care, helping parents or relatives, and working on land or garden plot. Subdomain activities for active leisure PA included ball sports, jogging, swimming, ice-skating, skiing, exercise equipment, dancing, aerobics, karate, and boxing. The formula for determining the domain-specific MET-hours per week is as follows:

$(\text { Domain MET-hours per week) })_{a, i}=\sum_{s=1}^{s} \mathrm{Time}_{s, i} \times \mathrm{MET}_{s, i}$,

where $i$ denotes an individual, $a$ denotes PA domains, and $s$ denotes subdomains. As for sedentary leisure time, the RLMS only asks about time spent watching television or videos and so we were unable to account for other sedentary leisure activities such as reading, listening to music, etc. (all while sitting).

Following the determination of the MET-hours per week from individuals for occupational, domestic, travel, and active leisure domains, as well as sedentary leisure time, weighted averages were determined for each RLMS Round. Post-stratification weights for individuals that fit the data to the multivariate distribution of location, age, and gender were used. Average values by Round were determined for adults 18-60 y and stratified by gender.

While data for occupational PA was available across all RLMS Rounds, data for domestic, travel, active leisure 
and sedentary leisure was less complete. Data on domestic PA was available for Rounds 6-8 $(1995,1996,1998)$ and Rounds 15-18 (2006-2009); travel PA data was only available for Rounds 6-14 (1995-2005); active leisure PA data was available for all RLMS Rounds except Round 16 and 17 (2007-2008). Meanwhile, data on sedentary time was only available in two Rounds (Rounds 10 and 11) from 2001 and 2002. Therefore, with the exception of sedentary time, linear interpolation was conducted to determine average values for the missing Rounds across the activity domains.

\section{Changes in PA over time}

Measures of change were calculated for all PA domains. The annualized change between time 1 (1995) and time 2 (varies by PA domain) was calculated by dividing the difference in the MET-hours per week between the two time points by the number of years between the two time points. The total percent change between time 1 and time 2 was determined by dividing the change between time 1 and time 2 by the time 1 MET-hours per week value; the result was multiplied by 100 to get a percentage. Lastly, the annualized percent change between time 1 and time 2 was determined by dividing the total percent change by the number of years between the two time points.

\section{Forecasting into 2020 and 2030}

Estimated levels of PA for each domain in 2020 and 2030 were determined using three approaches: (a) using the slope from the last six Rounds of data (2006-2011) only; (b) using the slope from the last four Rounds of data (2008-2011) only, which included 2 years of economic downturn followed by two years of economic growth; (c) using three-year moving averages. The approach using the slope from the last six or four Rounds of data is based on the assumption that trends over time are linear. The total percent change between 1995 and 2020 or 2030 was also determined by dividing the change from 1995 to 2020 or 2030 by the 1995 MET-hours per week value; the result was multiplied by 100 to get a percentage.

\section{Results}

Average MET-hours per week for all PA domains from 1995 to 2011 and forecasted for 2020 and 2030 for Adults (18-60 y) are shown in Table 2. The same estimates are shown graphically in Figure 1a-1c. Total PA was 282.9 MET-hours per week in 1995 and declined to 231.7 in 2011. Total PA is projected to decrease to 216.5 MET-hours per week in 2020 and to 193 MET-hours per week in 2030. Among male adults, occupational PA followed by travel PA constituted the greatest components of total PA from 1995 to 2011. In contrast, domestic PA followed by occupational PA contributed most to total PA among female adults from 1995 to 2011. MET-hours per week from active leisure were relatively low for both genders. Average weekly time spent in each domain by gender is included in Table 3.

Over a relatively short period of time (1995 to 1998), notable declines in occupational, domestic and travel PA were found (Table 2; Figure 1a-1c). From 1995 to 1998, occupational PA dropped by $22 \%$ (112.8 to 87.5 METhours per week), domestic PA fell by $21 \%$ (90.5 to 71.7 MET-hours per week), and travel PA dropped by $17 \%$ (77.9 to 64.3 MET-hours per week). Total PA METhours per week declined by 51.1 MET-hours per week among males and by 61.8 MET-hours per week among females from 1995 to 1998. In the ensuing years (19992005), PA increased and then stabilized across all domains. From 2006 and beyond, increases in occupational PA and declines in travel PA were seen.

Among the subset of adults in 2001 for whom there was data on sedentary leisure (television and video watching), the average hours spent per week was 18.5 and average MET-hours per week was 24.1. MET-hours per week of sedentary leisure was higher among male versus female adults in 2001 (24.9 and 23.4, respectively). Among the subset of adults in 2002, the average hours spent per week in sedentary activity was 20.7 and the average MET-hours per week was 26.9. Again, METhours per week of sedentary leisure was higher among male versus female adults (28.0 and 26.0, respectively). However, because the measure of sedentary leisure was limited to television and video watching, these are likely underestimates. In addition, with only two Rounds of data available for this measure for a subset, we were unable to reliably interpolate for the years prior and after.

Annualized changes, total \% changes, and annualized $\%$ changes between time 1 and time 2 for all PA domains using observed data are shown in Table 4. The greatest changes were in travel PA (i.e., largest annual and relative declines in travel PA); these declines were consistent among males and females. Females also experienced declines in domestic PA over time, with a $13.5 \%$ relative decline in MET-hours per week from 1995 to 2009. Annualized changes for occupational and active leisure PA were less distinct among all adults and by gender.

Forecasted changes in occupational, domestic, travel and active leisure PA (MET-hrs/week) for Adults (18-60 y) for 2020 and 2030 are shown in Table 5. We found that depending on the approach used, the forecasted PA levels for 2020 and 2030 can vary substantially. Forecasted total PA and travel PA values were very similar between using the 2006-2011 slope and using the 2008-2011 slope. Because the 2006-2011 slope provided the middle value for occupational PA, which was the main contributor to total $\mathrm{PA}$, we chose to focus on this value. However, we do note the difference. 
Table 2 Average MET-hours per week for activity domains from RLMS 1995 to 2011 and forecasted for 2020 and $2030^{a}$ for adults (18-60 y) by gender ${ }^{b}$

\begin{tabular}{|c|c|c|c|c|c|c|c|c|c|c|c|c|c|c|c|c|c|c|c|}
\hline \multirow{2}{*}{$\begin{array}{l}\text { Activity } \\
\text { domain }\end{array}$} & \multirow[b]{2}{*}{1995} & \multirow[b]{2}{*}{1996} & \multicolumn{17}{|c|}{ Average MET-hours per week by survey year } \\
\hline & & & 1997 & 1998 & 1999 & 2000 & 2001 & 2002 & 2003 & 2004 & 2005 & 2006 & 2007 & 2008 & 2009 & 2010 & 2011 & 2020 & 2030 \\
\hline \multicolumn{20}{|c|}{ Occupational PA } \\
\hline All Adults & 112.8 & 110.3 & 98.9 & 87.5 & 93.5 & 99.4 & 100.4 & 100.8 & 00.4 & 102.4 & 101.8 & 117.2 & 116.1 & 118.4 & 115.6 & 116.9 & 114.4 & 112.0 & 107.7 \\
\hline Males & 137.4 & 132.6 & 119.5 & 106.4 & 112.2 & 118.0 & 117.9 & 116.4 & 114.2 & 117.4 & 118.7 & 141.3 & 135.3 & 138.5 & 133.1 & 138.8 & 135.0 & 129.1 & 121.5 \\
\hline Females & 89.8 & 89.4 & 79.3 & 69.3 & 75.3 & 81.4 & 83.4 & 85.8 & 86.8 & 88.0 & 85.7 & 95.4 & 97.8 & 99.3 & 98.9 & 96.2 & 95.4 & 95.6 & 94.0 \\
\hline \multicolumn{20}{|c|}{ Domestic PA } \\
\hline Adults & 90.5 & 89.3 & 80.5 & 71.7 & 76.7 & 81.6 & 81.0 & 80.3 & 79.6 & 78.9 & 78.2 & 71.3 & 77.9 & 77.3 & 80.5 & 74.8 & 74.1 & 78.4 & 80.6 \\
\hline Males & 45.7 & 47.2 & 42.3 & 37.3 & 39.8 & 42.3 & 42.0 & 41.7 & 41.4 & 41.1 & 40.8 & 37.5 & 38.6 & 39.5 & 44.8 & 39.3 & 39.0 & 44.5 & 48.9 \\
\hline Females & 132.3 & 128.6 & 116.7 & 104.9 & 111.8 & 118.7 & 117.7 & 116.6 & 115.6 & 114.6 & 113.5 & 103.0 & 115.0 & 113.1 & 114.4 & 108.4 & 107.3 & 111.3 & 112.3 \\
\hline \multicolumn{20}{|l|}{ Travel PA } \\
\hline | Adults & 77.9 & 72.8 & 68.5 & 64.3 & 67.9 & 71.6 & 57.9 & 59.5 & 57.4 & 54.8 & 57.1 & 51.8 & 49.7 & 47.6 & 45.4 & 43.3 & 41.1 & 24.0 & 2.6 \\
\hline Males & 81.7 & 75.5 & 72.1 & 68.8 & 71.4 & 74.1 & 59.7 & 61.5 & 60.0 & 57.2 & 59.3 & 53.6 & 51.3 & 49.0 & 46.7 & 44.4 & 42.1 & 23.7 & 0.7 \\
\hline Females & 74.5 & 70.3 & 65.1 & 60.0 & 64.6 & 69.3 & 56.3 & 57.7 & 55.0 & 52.6 & 55.0 & 50.1 & 48.1 & 46.1 & 44.1 & 42.1 & 40.1 & 24.2 & 4.2 \\
\hline \multicolumn{20}{|c|}{ Active leisure PA } \\
\hline | Adults & 1.7 & 1.8 & 2.2 & 2.6 & 2.7 & 2.8 & 2.8 & 2.9 & 2.9 & 2.5 & 2.6 & 2.1 & 2.4 & 2.4 & 2.0 & 2.3 & 2.1 & 2.1 & 2.0 \\
\hline Males & 2.4 & 2.5 & 3.0 & 3.5 & 3.8 & 4.0 & 3.8 & 3.8 & 4.0 & 3.6 & 3.7 & 2.8 & 3.2 & 3.2 & 2.7 & 3.0 & 2.7 & 2.5 & 2.1 \\
\hline Females & 1.0 & 1.1 & 1.3 & 1.6 & 1.7 & 1.7 & 1.8 & 2.0 & 1.7 & 1.5 & 1.5 & 1.4 & 1.6 & 1.6 & 1.4 & 1.6 & 1.6 & 1.8 & 2.0 \\
\hline
\end{tabular}

Total PA

$\begin{array}{llllllllllllllllllll}\text { All Adults } & 282.9 & 274.1 & 250.1 & 226.1 & 240.8 & 255.5 & 242.1 & 243.5 & 240.3 & 238.7 & 239.7 & 242.4 & 246.0 & 245.7 & 243.5 & 237.2 & 231.7 & 216.5 & 193.0\end{array}$

$\begin{array}{lllllllllllllllllllll}\text { Males } & 267.2 & 257.8 & 236.9 & 216.1 & 227.2 & 238.3 & 223.4 & 223.4 & 219.6 & 219.3 & 222.5 & 235.2 & 228.4 & 230.3 & 227.3 & 225.5 & 218.9 & 199.7 & 173.1\end{array}$

$\begin{array}{lllllllllllllllllllll}\text { Females } & 297.6 & 289.3 & 262.5 & 235.8 & 253.4 & 271.1 & 259.2 & 262.0 & 259.1 & 256.8 & 255.6 & 249.9 & 262.5 & 260.1 & 258.8 & 248.4 & 244.4 & 232.7 & 212.4\end{array}$

${ }^{\mathrm{a}}$ Forecasting based on using 2006-2011 slopes are presented for all domains for 2020 and 2030.

${ }^{b}$ Italicized values were determined from linear interpolation for domestic PA from 2000-2005 and 2010-2011, for travel PA from 2006-2011, for active leisure PA for 2007 and 2008, and for all domains in 1997 and 1999.

Occupational PA fell between 1995 and 2020/2030 when using the 2006-2011 (and 2008-2011) slope to forecast, but rose slightly when using the three-year moving averages. For domestic PA, there was a decline regardless of the approach used, but the decline using the 2008-2011 slope was the greatest, while the decline using the 2006-2011 slope was the gentlest. In addition, while the forecasted travel PA using all approaches showed a decline since 1995, the three-year moving averages approach yielded the smallest decline. The total \% change presented therefore provides the mid-point estimate of the relative forecasted change between 1995 and 2020 or 2030. In looking at these, we see that the greatest declines are forecasted to occur in travel PA; these declines are consistent among males and females. Declines in domestic PA are also expected, with declining rates being greater among females versus males. Occupational PA is forecasted to decrease among males, but increase among females. Meanwhile, little change is expected in MET-hours per week from active leisure PA for males, but females are forecasted to increase their active leisure PA although the absolute level is still very low.

\section{Discussion}

Using nationally representative data from a country experiencing major economic transitions, we provide a comprehensive look at PA patterns and projections in Russian adults over a 16-year time period. Early in this time period (1995-1998), we document how a significant financial crisis coincided with domain-specific reductions in PA. In the ensuing years of economic recovery, our findings show corresponding increases in PA across all domains. Overall declines in total PA (namely in domestic and travel PA) are consistent with international trends characterized by more modern lifestyles and economic growth [1,9]. Projections in PA for 2020 and 2030 indicate troubling trends if no action is taken, thus domain-specific initiatives to prevent further PA declines are imperative.

PA reductions from 1995 to 1998 occurred when Russia was experiencing decreased economic productivity, political and economic instability, rising poverty, and other challenges that culminated in the Russian financial crisis of 1998 [17,26,30-32]. Occupational, domestic, and travel PA reached their lowest points in 1998, but later increased and evened out during the period of economic 


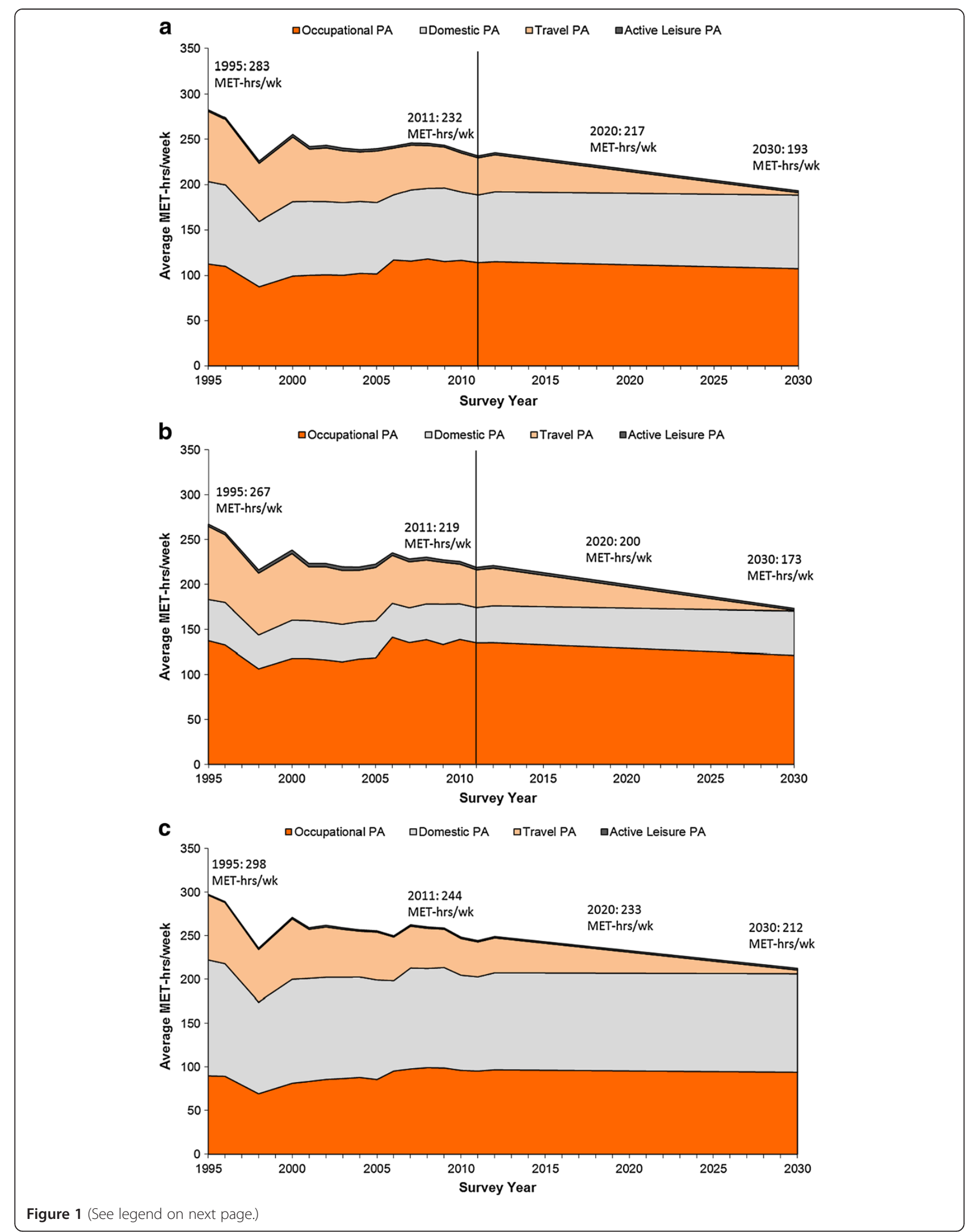


(See figure on previous page.)

Figure 1 Average MET-hours per week from PA for adults (18-60 y) and by gender for RLMS 1995-2011 and forecasted for 2020-2030. a. Average MET-hours/week from PA for Adults (18-60 y) for RLMS 1995-2011 and forecasted for 2020-2030. b. Average MET-hours/week from PA for Males (18-60 y) for RLMS 1995-2011 and forecasted for 2020-2030. c. Average MET-hours/week from PA for Females (18-60 y) for RLMS 1995-2011 and forecasted for 2020-2030.

recovery from 1999 to 2006. Effects of the milder recession in 2008-2009 were less notable on PA patterns. Therefore, our findings suggest that trends in domainspecific PA correlate with patterns of economic instability and recovery.

Among male adults, the largest contributor to total PA was occupational PA followed by travel PA. In contrast, domestic PA followed by occupational PA contributed most to total PA among females adults. Total PA was 282.9 MET-hours per week in 1995 and declined to 231.7 in 2011. The greatest relative declines are occurring in travel PA, and female adults are also exhibiting significant declines in domestic PA. The declines in domestic PA among females are concurrent with increases in occupational PA; these trends are likely resultant from more women entering the workforce, women working longer hours, and a shifting of time demands away from the home and toward work. Changes in active leisure PA are less distinct. In comparing these results to past results for the United States, United Kingdom, Brazil, India and China [9], we found that the trends in Russia (excluding occupational PA) are following what has been observed in these five countries. Declines in travel and domestic PA have been well-documented across countries, mainly driven by increases in passive travel and greater access to modern technology for home production activities [23,33-38]. While it is surprising that Russian occupational PA has not declined more, this may reflect to some extent the lack of modernization of the dominant manufacturing sector and the lack of a shift in occupational structure toward a much greater proportion in the service sector found in most higher income countries as income improves significantly $[39,40]$.

Total PA is projected to decrease to 216.5 MET-hours per week in 2020 and to 193.0 MET-hours per week in 2030. The 23.5 MET-hours per week reduction from 2020 to 2030 is roughly equivalent to 3.9 to 7.8 hours of moderate PA. These projections are largely influenced by decreased travel and domestic PA, whereas forecasted occupational and active leisure PA patterns are more stable over time. The more stable occupational PA patterns may be a consequence of this activity reaching a lowest possible limit (bottoming out effect). Stable active leisure PA patterns are expected without time use

Table 3 Average hours per week for activity domains from RLMS 1995 to $2011^{\text {a }}$

\begin{tabular}{|c|c|c|c|c|c|c|c|c|c|c|c|c|c|c|c|}
\hline \multirow{2}{*}{$\begin{array}{l}\text { Activity } \\
\text { domain }\end{array}$} & \multicolumn{15}{|c|}{ Average hours per week by survey year } \\
\hline & 1995 & 1996 & 1998 & 2000 & 2001 & 2002 & 2003 & 2004 & 2005 & 2006 & 2007 & 2008 & 2009 & 2010 & 2011 \\
\hline \multicolumn{16}{|c|}{ Occupational PA } \\
\hline All Adults & 31.1 & 30.5 & 24.5 & 27.6 & 28.1 & 28.3 & 28.0 & 28.5 & 28.3 & 33.3 & 32.9 & 33.2 & 32.6 & 33.2 & 32.7 \\
\hline Males & 34.7 & 33.4 & 27.1 & 29.8 & 30.1 & 29.7 & 29.0 & 29.6 & 29.9 & 36.2 & 34.6 & 35.0 & 33.8 & 35.6 & 34.8 \\
\hline Females & 27.8 & 27.9 & 21.9 & 25.5 & 26.2 & 26.9 & 27.1 & 27.5 & 26.7 & 30.8 & 31.2 & 31.6 & 31.5 & 31.0 & 30.7 \\
\hline \multicolumn{16}{|c|}{ Domestic PA } \\
\hline All Adults & 29.0 & 28.6 & 23.6 & 26.5 & 26.3 & 26.2 & 26.0 & 25.8 & 25.6 & 23.3 & 25.8 & 25.7 & 26.2 & 24.8 & 24.6 \\
\hline Males & 13.5 & 13.9 & 11.5 & 12.8 & 12.8 & 12.8 & 12.8 & 12.7 & 12.7 & 11.8 & 12.3 & 12.7 & 13.8 & 12.6 & 12.5 \\
\hline Females & 43.6 & 42.3 & 35.2 & 39.4 & 39.1 & 38.8 & 38.5 & 38.2 & 37.9 & 34.1 & 38.5 & 38.1 & 38.1 & 36.3 & 36.0 \\
\hline \multicolumn{16}{|l|}{ Travel PA } \\
\hline All Adults & 26.0 & 24.3 & 21.4 & 23.9 & 19.3 & 19.8 & 19.1 & 18.3 & 19.0 & 17.3 & 16.6 & 15.9 & 15.1 & 14.4 & 13.7 \\
\hline Males & 27.2 & 25.2 & 22.9 & 24.7 & 19.9 & 20.5 & 20.0 & 19.1 & 19.8 & 17.9 & 17.1 & 16.3 & 15.6 & 14.8 & 14.0 \\
\hline Females & 24.8 & 23.4 & 20.0 & 23.1 & 18.8 & 19.2 & 18.3 & 17.5 & 18.3 & 16.7 & 16.0 & 15.4 & 14.7 & 14.0 & 13.4 \\
\hline \multicolumn{16}{|c|}{ Active leisure PA } \\
\hline All Adults & 0.3 & 0.3 & 0.4 & 0.5 & 0.5 & 0.5 & 0.5 & 0.4 & 0.4 & 0.3 & 0.4 & 0.4 & 0.3 & 0.4 & 0.3 \\
\hline Males & 0.4 & 0.4 & 0.6 & 0.6 & 0.6 & 0.6 & 0.7 & 0.6 & 0.6 & 0.4 & 0.5 & 0.5 & 0.4 & 0.5 & 0.5 \\
\hline Females & 0.1 & 0.2 & 0.2 & 0.3 & 0.3 & 0.3 & 0.3 & 0.2 & 0.2 & 0.2 & 0.3 & 0.3 & 0.2 & 0.3 & 0.2 \\
\hline
\end{tabular}

altalicized values were determined from linear interpolation for domestic PA from 2000-2005 and 2010-2011, for travel PA from 2006-2011, for active leisure PA for 2007 and 2008. 
Table 4 Observed changes in occupational, domestic, travel and active leisure PA (MET-hrs/week) for adults (18-60 y) ${ }^{a}$

\begin{tabular}{|c|c|c|c|c|c|}
\hline PA domain (Survey years) & $\begin{array}{r}\text { MET-hours } \\
\text { per week } \\
\text { at time } 1 \\
\end{array}$ & $\begin{array}{r}\text { MET-hours } \\
\text { per week } \\
\text { at time } 2 \\
\end{array}$ & $\begin{array}{r}\text { Annualized change } \\
\text { between time } \\
1 \text { and time } 2 \\
\end{array}$ & $\begin{array}{r}\text { Total \% change } \\
\text { between time } \\
1 \text { and time } 2 \\
\end{array}$ & $\begin{array}{r}\text { Annualized \% } \\
\text { change between } \\
\text { time } 1 \text { and time } 2\end{array}$ \\
\hline \multicolumn{6}{|l|}{ Occupational PA (1995-2011) } \\
\hline All Adults & 112.8 & 114.4 & 0.1 & 1.4 & 0.1 \\
\hline Males & 137.4 & 135.0 & -0.1 & -1.7 & -0.1 \\
\hline Females & 89.8 & 95.4 & 0.3 & 6.2 & 0.4 \\
\hline \multicolumn{6}{|l|}{ Domestic PA (1995-2009) } \\
\hline All Adults & 90.5 & 80.5 & -0.7 & -11.0 & -0.8 \\
\hline Males & 45.7 & 44.8 & -0.1 & -2.0 & -0.1 \\
\hline Females & 132.3 & 114.4 & -1.3 & -13.5 & -1.0 \\
\hline \multicolumn{6}{|l|}{ Travel PA (1995-2005) } \\
\hline All Adults & 77.9 & 57.1 & -2.1 & -26.8 & -2.7 \\
\hline Males & 81.7 & 59.3 & -2.2 & -27.5 & -2.7 \\
\hline Females & 74.5 & 55.0 & -1.9 & -26.2 & -2.6 \\
\hline \multicolumn{6}{|l|}{ Active leisure PA (1995-2011) } \\
\hline All Adults & 1.7 & 2.1 & $<0.1$ & 27.6 & 1.7 \\
\hline Males & 2.4 & 2.7 & $<0.1$ & 13.0 & 0.8 \\
\hline Females & 1.0 & 1.6 & $<0.1$ & 63.2 & 4.0 \\
\hline
\end{tabular}

changes across the domains (e.g., increased active leisure PA requires time use reductions in sedentary activities or in other domains) or with increases in the intensity of active leisure activities. Projected reductions in other domains are highly probable without action.

Development of domain-specific initiatives, particularly for travel and active leisure PA, are needed to promote more active travel and leisure activities. Focusing initiatives in active travel and leisure domains have proven effective in improving PA [33,41-45] and could help counteract projected declines in total PA. Efforts can range from congestion charging schemes to reduce car use, with a resultant increase in cycling and walking for transport and other positive outcomes, such as improved air quality, lower carbon footprint, lower noise pollution and lower congestion [46], to a growing array of transportation options. However, without disincentives to car ownership and use, better active transport infrastructure, and improved mass transit, these changes are not likely to occur.

We faced some data limitations that warrant explanation. First, there was a lack of completeness in the survey questions asked over the various rounds of the RLMS. Specifically, some questions were included in some but not all of the RLMS rounds. Consequently, we had to conduct linear interpolation for domestic PA from 2000-2005 and 2010-2011, for travel PA from 2006-2011, and for active leisure PA for 2007 and 2008. These steps might have affected the precision of our forecasts in particular. Additionally, the RLMS questions on travel PA and sedentary time were limited in terms of the travel modes included and type of sedentary activities. Lastly, the way in which the RLMS collects information about time spent in various domains does not allow for simultaneous activities (e.g., caring for a child while preparing food), and so may overestimate PA. However, for the purposes of understanding trends, so long as the cause and degree of mis-estimation is random and consistent over time, we do not believe this is a problem.

\section{Conclusion}

Our study provides an initial look at nationallyrepresentative, domain-specific PA patterns and projections for Russian adults over an extended time period marked by major economic change. These results add to earlier work that documents the dramatic global trends in declines in PA and rises in inactivity in the US, UK, Brazil and India [9]. As a populous and aging country, the long term health implications of these trends can be significant. More needs to be done to encourage movement in Russia via investments into infrastructure, interventions and initiatives that promote PA across all domains of living, particularly active travel, active leisure (exercise) as well as certain domestic activities (e.g., gardening). In order for these interventions and initiatives to be effective, they must recognize competing time demands and incorporate strategies promoting increased time and/or intensity spent in active travel, active leisure, and domestic domains. 
Table 5 Forecasted changes in occupational, domestic, travel and active leisure PA (MET-hrs/week) for adults (18-60 y)

\begin{tabular}{|c|c|c|c|c|c|c|c|c|c|}
\hline PA domain & $\begin{array}{r}\text { MET-hrs/wk } \\
\text { in } 1995\end{array}$ & $\begin{array}{r}\text { MET-hrs/wk } \\
\text { in } 2020 \text { using } \\
2006-2011 \text { slope }\end{array}$ & $\begin{array}{r}\text { MET-hrs/wk } \\
\text { in } 2020 \text { using } \\
2008-2011 \text { slope }\end{array}$ & $\begin{array}{r}\text { MET-hrs/wk in } \\
2020 \text { using 3-year } \\
\text { moving averages }\end{array}$ & $\begin{array}{r}\text { Total \% change } \\
\text { from } 1995 \\
\text { to } 2020^{\mathrm{a}}\end{array}$ & $\begin{array}{r}\text { MET-hrs/wk } \\
\text { in } 2030 \text { using } \\
2006-2011 \text { slope }\end{array}$ & $\begin{array}{r}\text { MET-hrs/wk } \\
\text { in } 2030 \text { using } \\
2008-2011 \text { slope }\end{array}$ & $\begin{array}{r}\text { MET-hrs/wk in } \\
2030 \text { using 3-year } \\
\text { moving averages }\end{array}$ & $\begin{array}{r}\text { Total \% change } \\
\text { from } 1995 \\
\text { to } 2030^{\mathrm{a}}\end{array}$ \\
\hline \multicolumn{10}{|c|}{ Occupational PA } \\
\hline All Adults & 112.8 & 112.0 & 106.0 & 115.5 & 0.8 & 107.7 & 95.1 & 115.5 & -1.1 \\
\hline Males & 137.4 & 129.1 & 131.7 & 135.8 & -3.6 & 121.5 & 126.8 & 135.8 & -6.3 \\
\hline Females & 89.8 & 95.6 & 83.7 & 96.3 & 6.8 & 94 & 69.2 & 96.3 & 5.9 \\
\hline \multicolumn{10}{|l|}{ Domestic PA } \\
\hline All Adults & 90.5 & 78.4 & 62.1 & 75.4 & -15.0 & 80.6 & 46.9 & 75.4 & -13.8 \\
\hline Males & 45.7 & 44.5 & 34.1 & 40.1 & -7.4 & 48.9 & 27.1 & 40.1 & -2.6 \\
\hline Females & 132.3 & 111.3 & 88.7 & 108.9 & -16.8 & 112.3 & 65.5 & 108.9 & -16.4 \\
\hline \multicolumn{10}{|l|}{ Travel PA } \\
\hline All Adults & 77.9 & 24.0 & 24.0 & 42.6 & -57.3 & 2.6 & 2.7 & 42.6 & -71.0 \\
\hline Males & 81.7 & 23.7 & 23.7 & 43.6 & -58.8 & 0.7 & 0.7 & 43.6 & -72.9 \\
\hline Females & 74.5 & 24.2 & 24.2 & 41.4 & -56.0 & 4.2 & 4.2 & 41.4 & -69.4 \\
\hline \multicolumn{10}{|c|}{ Active leisure PA } \\
\hline All Adults & 1.7 & 2.1 & 1.7 & 2.2 & 28.8 & 2.0 & 1.2 & 2.2 & 25.8 \\
\hline Males & 2.4 & 2.5 & 1.8 & 2.8 & 9.0 & 2.1 & 0.6 & 2.8 & 0.8 \\
\hline Females & 1.0 & 1.8 & 1.7 & 1.6 & 77.4 & 2.0 & 1.8 & 1.6 & 87.9 \\
\hline \multicolumn{10}{|l|}{ Total PA } \\
\hline All Adults & 282.9 & 216.5 & 216.5 & 235.7 & -20.1 & 192.9 & 193.0 & 235.7 & -24.2 \\
\hline Males & 267.2 & 199.8 & 199.7 & 222.3 & -21.0 & 173.2 & 173.1 & 222.3 & -26.0 \\
\hline Females & 297.6 & 232.9 & 232.7 & 248.2 & -19.2 & 212.5 & 212.4 & 248.2 & -22.6 \\
\hline
\end{tabular}

${ }^{\mathrm{a}}$ The 2020 or 2030 value used in the total \% change measure was the midpoint value from the 2006-2011 slope and moving averages calculations. 
From a methodological standpoint, the inclusion of time and intensity measures for occupational activities in the RLMS enabled assessment of three distinct approaches for the estimation of MET values for occupational PA. Comparison of Approaches A and B yielded consistent findings, thus supporting the robustness of the widely used approach of assigning MET values to occupations based on the Compendium of Physical Activities. Additional methodological exploration was conducted with respect to PA projections, given the application of three approaches for estimating domain-specific levels of PA in 2020 and 2030. Further study is planned to examine determinants of the PA trends and also to utilize RLMS longitudinal data to compare age, period, and cohort effects of environmental and individual factors on PA behaviors.

\section{Abbreviations \\ MET: Metabolic equivalent of tasks; PA: Physical activity; IPAQ: International physical activity questionnaire; GPAQ: Global physical activity questionnaire; RLMS: Russia Longitudinal Monitoring Survey.}

\section{Competing interests}

The work presented in this paper was commissioned by funds from Nike, Inc. The authors completed the manuscript independently with assistance of reviewers.

\section{Authors' contributions}

BMP designed the physical activity measures for the RLMS. TDW conducted the data cleaning, analyses and drafted the manuscript. SWN led the study methods, approach and data interpretation, drafted and revised the manuscript. BMP is the co-PI of the RLMS study and participated in the methods and approach, reviewed and revised the manuscript. All authors read and approved the final manuscript. None of the authors has conflicts of interest with respect to this manuscript.

\section{Acknowledgements}

We thank Ms Frances Dancy for administrative assistance; and Lisa MacCallum, Nithya Gopu and Lindsay Frey-Martinez, our liaisons at Nike, Inc.

Received: 28 August 2013 Accepted: 21 January 2014

Published: 30 January 2014

\section{References}

1. Popkin BM, Gordon-Larsen P: The nutrition transition: worldwide obesity dynamics and their determinants. Int J Obes Relat Metab Disord 2004, 28(Suppl 3):S2-S9.

2. Joint WHO/FAO Expert Consultation: Diet, Nutrition, and the Prevention of Chronic Diseases. Report of a joint WHO/FAO expert consultation. Geneva: WHO technical report series; 2003:916.

3. Kumanyika $S$, et al: Obesity prevention: the case for action. Int J Obes Relat Metab Disord 2002, 26(3):425-436.

4. Swinburn BA, et al: The global obesity pandemic: shaped by global drivers and local environments. Lancet 2011, 378(9793):804-814.

5. Bauman A, et al: The International Prevalence Study on Physical Activity: results from 20 countries. Int J Behav Nutr Phys Act 2009, 6:21.

6. Craig CL, et al: International physical activity questionnaire: 12-country reliability and validity. Med Sci Sports Exerc 2003, 35(8):1381-1395.

7. Guthold $R$, et al: Worldwide variability in physical inactivity a 51-country survey. Am J Prev Med 2008, 34(6):486-494.

8. Ng SW, Norton EC, Popkin BM: Why have physical activity levels declined among Chinese adults? Findings from the 1991-2006 China Health and Nutrition Surveys. Soc Sci Med 2009, 68(7):1305-1314.

9. Ng SW, Popkin BM: Time use and physical activity: a shift away from movement across the globe. Obes Rev 2012, 13(8):659-680.

10. Juneau CE, Potvin L: Trends in leisure-, transport-, and work-related physical activity in Canada 1994-2005. Prev Med 2005, 51(5):384-386.
11. Stamatakis E, Ekelund U, Wareham NJ: Temporal trends in physical activity in England: the Health Survey for England 1991 to 2004. Prev Med 2007, 45(6):416-423

12. Monteiro CA, et al: A descriptive epidemiology of leisure-time physical activity in Brazil, 1996-1997. Rev Panam Salud Publica 2003, 14(4):246-254.

13. World Bank: Population ranking table. http://data.worldbank.org/datacatalog/Population-ranking-table.

14. International Monetary Fund: World Economic Outlook Database. 2013. http://www.imf.org/external/pubs/ft/weo/2013/01/weodata/index.aspx.

15. Gorodnichenko Y, Peter KS, Stolyarov D: Inequality and Volatility Moderation in Russia: Evidence from Micro-Level Panel Data on Consumption and Income. Rev Econ Dyn 2010, 13(1):209-237.

16. World Bank, Russian Economic Report: Moderating Risks, Bolstering Growth. T.W.B.i. Russia, Editor: World Bank; 2012.

17. Dore AR, Adair LS, Popkin BM: Low income Russian families adopt effective behavioral strategies to maintain dietary stability in times of economic crisis. J Nutr 2003, 133(11):3469-3475.

18. Jahns L, Baturin A, Popkin BM: Obesity, diet, and poverty: trends in the Russian transition to market economy. Eur J Clin Nutr 2003, 57(10):1295-1302.

19. Stillman S, Thomas D: Nutritional Status During an Economic Crisis: Evidence from Russia. Econ J 2008, 118(531):1385-1417.

20. Ainsworth BE, et al: 2011 Compendium of Physical Activities: a second update of codes and MET values. Med Sci Sports Exerc 2011, 43(8):1575-1581.

21. Tudor-Locke C, Ainsworth BE, Popkin BM: Patterns of physical activity and overweight among 7-13-year-old Russian children: a 7-year nationally representative monitoring study. Research Quarterly For Exercise and Sport 2008, 79(1):10-17.

22. Tudor-Locke C, Ainsworth BE, Popkin BM: Active commuting to school: an overlooked source of childrens' physical activity? Sports Med 2001, 31(5):309-313.

23. Popkin BM: The nutrition transition and its health implications in lowerincome countries. Public Health Nutr 1998, 1(1):5-21.

24. Dellava JE, Bulik CM, Popkin BM: Prices Changes Alone Are Not Adequate to Produce Long-Term Dietary Change. J Nutr 2010, 140(10):1887-91. jn.110.125419.

25. Mroz TA, Popkin BM: Poverty and the Economic Transition in the Russian Federation. Econ Dev Cult Chang 1995, 44(1):1-31.

26. Lokshin M, Popkin BM: The Emerging Underclass in the Russian Federation: Income Dynamics, 1992-1996. Econ Dev Cult Chang 1999, 47(4):803-829.

27. International Labour Office: International Standard Classification of Occupations: ISCO-88. http://www.llo.org/public/english/bureau/stat/isco/ isco88/index.htm.

28. Carolina Population Center: Occupational Coding. http://www.cpc.unc.edu/ projects/rlms-hse/data/documentation/occupationalcoding.

29. Tudor-Locke C, Washington TL, Ainsworth BE, Troiano RP: Linking theAmerican Time Use Survey (ATUS) and the Compendium of Physical Activities:Methods and Rationale. J Phys Act Health 2009, 6(3):347-53.

30. Zohoori N, Mroz TA, Popkin B, Glinskaya E, Lokshin M, Mancini D, Kozyreva P, Kosolapov M, Swafford M: Monitoring the Economic Transition in the Russian Federation and Its Implications for the Demographic Crisis-The Russian Longitudinal Monitoring Survey. World Dev 1998, 26(11):1977-93.

31. Mroz TA, Henderson L, Bontch-Osmolovsii M, Popkin BM: Monitoring Economic Conditions in the Russian Federation: The Russia Longitudinal Monitoring Survey 1992-2002. In Report submitted to the U.S. Agency for International Development., C.P. Center, Editor. Chapel Hill: University of North Carolina at Chapel Hill; 2003.

32. Jovanovic B: Russian Roller Coaster: Expenditure Inequality and Instability in Russia, 1994-98. Rev Income Wealth 2001, 47(2):251-71.

33. Bell AC, Ge K, Popkin BM: The road to obesity or the path to prevention: motorized transportation and obesity in China. Obes Res 2002, 10(4):277-83.

34. Monda $\mathrm{KL}$, et al: Longitudinal relationships between occupational and domestic physical activity patterns and body weight in China. Eur J Clin Nutr 2008, 62(11):1318-25.

35. Brownson RC, Boehmer TK, Luke DA: Declining rates of physical activity in the United States: What are the contributors? Annu Rev Public Health 2005, 26:421-443.

36. Brownson R, Boehmer T: Patterns and Trends in Physical Activity, Occupation, Transportation, Land Use, and Sedentary Behaviors. In Does 
the built environment influence physical activity? Examining the evidenceSpecial Report 282, Washington, DC. ed. National Research Council; 2005. ISBN 978-0-309-09498-6.

37. Pucher J, et al: Urban transport trends and policies in China and India: Impacts of rapid economic growth. Transp Rev 2007, 27(4):379-410.

38. Reis JP, et al: Nonoccupational physical activity by degree of urbanization and US geographic region. Med Sci Sports Exerc 2004, 36(12):2093-2098

39. Cianci M: Russia: What's Next? Transit Stud Rev 2010, 16(4):936-947.

40. Anikin V: Mode of Socio-Economic Development and Occupational Structure: The Case of Contemporary Russia. Transit Stud Rev 2013, 19(4):397-415.

41. Pucher J, Buehler R: Cycling for Everyone Lessons from Europe. Transp Res Rec 2008, 2074:58-65.

42. Pucher J, Buehler R: Making cycling irresistible: lessons from the Netherlands, Denmark and Germany. Transp Rev 2008, 28(4):495-528.

43. Pucher J, Komanoff C, Schimek P: Bicycling renaissance in North America?: recent trends and alternative policies to promote bicycling. Transp Res $A$ Policy Pract 1999, 33(7-8):625-654.

44. Matsudo $S M$, et al: Evaluation of a physical activity promotion program: the example of Agita Sao Paulo. Eval Program Plann 2006, 29(3):301-311.

45. Bell AC, Garrard J, Swinburn BA: Active transport to work in Australia: is it all downhill from here? Asia Pac J Public Health 2006, 18(1):62-8.

46. De Nazelle A, et al: Improving health through policies that promote active travel: a review of evidence to support integrated health impact assessment. Environ Int 2011, 37(4):766-77.

doi:10.1186/1479-5868-11-11

Cite this article as: Dearth-Wesley et al.: Estimated and forecasted trends in domain specific time-use and energy expenditure among adults in Russia. International Journal of Behavioral Nutrition and Physical Activity 2014 11:11.

\section{Submit your next manuscript to BioMed Central and take full advantage of:}

- Convenient online submission

- Thorough peer review

- No space constraints or color figure charges

- Immediate publication on acceptance

- Inclusion in PubMed, CAS, Scopus and Google Scholar

- Research which is freely available for redistribution 